\title{
The Number of Grafted Fragments Affects the Outcome of Testis Tissue Xenografting from Piglets into Recipient Mice
}

\author{
Sepideh Abbasi and Ali Honaramooz \\ Department of Veterinary Biomedical Sciences, Western College of Veterinary Medicine, \\ University of Saskatchewan, 52 Campus Drive, Saskatoon, SK, Canada S7N 5B4 \\ Correspondence should be addressed to Ali Honaramooz, ali.honaramooz@usask.ca
}

Received 3 May 2010; Accepted 31 May 2010

Academic Editor: Stefan Schlatt

Copyright ( $(2011$ S. Abbasi and A. Honaramooz. This is an open access article distributed under the Creative Commons Attribution License, which permits unrestricted use, distribution, and reproduction in any medium, provided the original work is properly cited.

To optimize the procedure for testis tissue xenografting, we grafted 2, 4, 8, or 16 small fragments of immature porcine testis tissue under the back skin of immunodeficient castrated mice ( $n=10$ mice/group). At 8 months post grafting, the graft recovery rate did not differ between groups; however, not only the total but also the average graft weights were higher (by $\sim 12$-fold and $\sim 2.5$-fold, resp.) in mice receiving 16 fragments than those receiving 2 fragments $(P<.05)$. The recipient mice with 16 fragments had the largest vesicular glands (indicators of testosterone release by the grafts) compared with those with 2 fragments $(P=.007)$. The grafts in the group of 16 fragments also had more $(P<.05)$ percentage of tubules with round spermatids than those of the group of mice receiving 2 fragments. Therefore, recipient mice can be grafted with at least 16 testis tissue fragments for optimal results.

\section{Introduction}

The neonatal testis contains immature interstitial Leydig cells and seminiferous cords enclosing gonocytes, the only germ cell type present and precursors of spermatogonial stem cells, as well as immature somatic Sertoli cells. During prepubertal development, the testis tissue undergoes a number of developmental changes to transform into a mature tissue capable of androgen release and spermatogenesis, a highly organized cyclic process that continuously produces haploid spermatozoa from diploid male germline cells [1]. The underlying mechanisms controlling this process and especially the maturational changes in the testis of humans and large animals are difficult to study in situ and are best to be studied in a proper model $[2,3]$.

In the absence of an in vitro model that can faithfully replicate testicular maturation and spermatogenesis [4], xenografting of testis tissue has emerged in recent years to overcome these limitations by providing an in vivo culture system. In this approach, small fragments of testis parenchyma from an immature donor of any mammalian species are grafted under the back skin of immunodeficient mice $[5,6]$. This strategy maintains the structural integrity and cell associations needed for the subsequent development of spermatogenesis. Testis tissue xenografting has been successful in inducing maturation in the grafted tissue and development leading up to complete spermatogenesis using a wide range of immature donor species including laboratory, farm, or companion animals as well as primates in a recipient mouse model [5-13]. Xenogeneic spermatozoa have been retrieved from testis tissue xenografts by mechanical dispersion and used for intracytoplasmic spermatozoa injection (ICSI) to confirm fertilization competence or to produce offspring even from newborn donor animals [5, 14-19]. Testis tissue xenografting has shown promise in a number of important applications such as allowing the study and manipulation of spermatogenesis, providing insights into testis function, and offering a new option for male germline preservation especially from neonatally lethal phenotypes and rare or endangered animals that die before puberty $[17,18,20-23]$.

Following the methodology described in the first reports of successful testis tissue xenografting $[5,6]$, most researchers have used 8 testis tissue fragments, of $\sim 1 \mathrm{~mm}^{3}$ (or $\sim 5 \mathrm{mg}$ ) each, to graft under the back skin of recipient mice. This number of grafts per mouse was chosen for practical reasons 
as 4 grafts could be easily grafted on either side of the midline and spaced out between the neck and sacral region. It is desirable to maximize the mass of harvested grafts; however, no study has systematically evaluated the optimum number of the initial tissue fragments that can result in the highest growth and development of the grafted testis tissue. Therefore, the objective of this study was to determine the effect of the initial number of porcine testis tissue fragments grafted per recipient mouse on the outcome of testis tissue xenografting.

\section{Materials and Methods}

2.1. Study Design. We examined the effect of using different numbers of testis tissue fragments per recipient mouse on the outcome of testis tissue xenografting. Groups of castrated immunodeficient mice ( $n=10 \mathrm{mice} /$ group) received 2,4 , 8 , or 16 fragments of donor testis tissue under the back skin. At 8 months postgrafting, the recipient mice were sacrificed and the visible xenografts were recovered. The retrieved xenografts were then evaluated for graft weight, recovery rate, and histological development. The weight of the vesicular glands in the recipient mice was also evaluated as an indication of androgen production by the testis grafts. Experimental procedures involving animals were approved by the University of Saskatchewan's Institutional Animal Care and Use Committee.

2.2. Donor Testis Tissue. Donor testis tissue was obtained through aseptic castration of 1 -week-old Yorkshire-cross piglets (Camborough-22 $\times$ Line 65, PIC Canada Ltd., Winnipeg, MB, Canada) at a swine facility. Immediately after castration, the testes were immersed in ice-cold Dulbecco's phosphate buffered saline (DPBS, Cat. No. 20-031-CV, Mediatech, Manassas, VA, USA) containing 2\% w/v antibiotic/antimycotic solution (Cat. No. 30-004-CI, Mediatech). The testes were transferred to the laboratory within $1 \mathrm{~h}$, where they were rinsed 3 times with DPBS and the tunica albuginea, rete testis, and overt connective tissues were removed. Small fragments of testis, approximately $5 \mathrm{mg}$ in weight or $1 \mathrm{~mm}^{3}$ in volume, were cut from the testis parenchyma using a scalpel and maintained in Dulbecco's modified Eagle's medium (DMEM, Cat. No. 10-013-CM, Mediatech) on ice until grafting within $2 \mathrm{~h}$. As a reference for graft development, samples of the fragments were fixed in Bouin's solution overnight, washed with and kept in 70\% v/v ethanol, and processed for histology.

2.3. Recipient Mice and Procedures for Xenografting of Testis Tissue. Male immunodeficient nude mice (NCr, nu/nu, Taconic, Germantown, NY, USA) were randomly assigned to one of four groups ( $n=10 \mathrm{mice} /$ group) to receive 2, 4,8 , or 16 testis tissue grafts. At the time of grafting, mice were $\sim 10$ wk old and maintained aseptically in groups of 10 in perplexiglass microinsulators in a room with controlled photoperiod (lights on from 0600 through 1800). The mice were provided with sterile water and mouse chow ad libitum.
At the time of surgery, the mice were anesthetized with intraperitoneal injection of ketamine hydrochloride $(100 \mathrm{mg} / \mathrm{kg}$; Ketalene, Bimeda-MTC, Cambridge, ON, Canada) and xylazine hydrochloride $(10 \mathrm{mg} / \mathrm{kg}$; Vet-A-Mix, Shenandoah, IA, USA). All recipient mice underwent castration using an abdominal midline approach. A transverse linear incision ( $\sim 5 \mathrm{~mm}$ in length) per planned graft was made into the back skin of each mouse, a small subcutaneous pouch was created using blunt dissection and a testis tissue fragment was placed in the subcutaneous pouch. Wound clips were used to close the incisions (Michel Clips $7.5 \mathrm{~mm}$, Miltex, York, PA, USA).

2.4. Gross and Histological Analysis. At 8 months postgrafting, the mice were anesthetised, sacrificed, and weighted. Visible xenografts were retrieved, weighted, and fixed in Bouin's solution overnight. The testis tissue xenografts were washed with and kept in 70\% ethanol solution prior to histological processing. After processing, the grafts were paraffin blocked and sectioned (at $6 \mu \mathrm{m}$ thickness) at the largest diameter. The tissue sections were stained with haematoxylin and eosin, and evaluated under light microscopy using a calibrated microscope (BX41, Olympus Inc., Markham, ON, Canada) equipped with a digital camera (DP71, Olympus Inc.).

From each mouse as the experimental unit, 16 digital micrographs were captured from randomly selected areas of the sectioned xenografts so each graft was represented in at least one micrograph. The micrographs were captured at 200x magnification and given codes that were unknown to the operator analyzing them. All seminiferous tubules (or up to 200, if there were more) in each micrograph were evaluated, and measured using a software (Image pro Express, version 6.0.0.319 for Windows XP/Professional, Media Cybernetics Inc, Bethesda, MD, USA). The endpoints for evaluation included the number of tubule cross sections to calculate the tubular density (per $\mathrm{mm}^{2}$ ), tubular diameter in the widest cross section, the morphology of seminiferous tubules, and the most advanced germ cell type in the tubules.

To evaluate the morphology of the seminiferous tubules and the most advanced germ cell type, we recorded the presence of (1) mature spermatozoa in the lumen of the seminiferous tubule cross section; (2) elongated spermatids as the most advanced germ cells; (3) round spermatids as the most advanced germ cells; (4) spermatocytes as the most advanced germ cells; (5) spermatogonia as the only type of germ cells; (6) Sertoli-cell-only tubule; and (7) complete tubular degeneration or fibrosis.

We also dissected out and weighed the vesicular glands to calculate the vesicular gland index. The index (\% of the vesicular gland weight/body weight) has been used as an indicator of the levels of bioactive androgens released by the xenografts $[5,16]$.

2.5. Statistical Analysis. Since the recipient mouse was considered an experimental unit, the data obtained from all testis tissue xenografts within a mouse were pooled. The evaluated endpoints were the mouse body weight $(\mathrm{g})$, graft recovery rate (\% of visible grafts retrieved compared with the original number of fragments grafted), total and 
average graft weight (mg), vesicular gland index (\%), seminiferous tubule diameter $(\mu \mathrm{m})$, tubular density $\left(/ \mathrm{mm}^{2}\right)$, the percentages of tubule cross sections with spermatozoa, elongated spermatids, round spermatids, and spermatocytes or spermatogonia as the most advanced germ cell type, in addition to the categories of seminiferous tubules containing Sertoli-cell-only or showing degeneration or fibrosis.

The data were analyzed for the effect of the number of testis tissue fragments using one-way ANOVA. The Pearson product-moment correlation coefficients were calculated for the mouse body weight, average or total graft weight, and the above-mentioned endpoints related to testis graft development. Data are expressed as means \pm SEM and $P<$ .05 was considered significant.

\section{Results}

3.1. Mouse Body Weight, Graft Weight, and Graft Recovery Rate. Out of 40 recipient mice, 3 died before the scheduled time of sacrifice and were thus excluded from the data. In the remaining 37 mice, the body weight did not differ among groups $(P=.2)$ and a total of 275 out of 294 grafts had survived (overall, $94 \%$ graft recovery). The graft recovery rate, ranging from $86 \%$ to $98 \%$, did not differ among the four groups of recipient mice $(P=.7$, Table 1$)$.

At 8 months postgrafting, the recovered grafts in all groups had increased in average weight, compared with the original weight of $5 \mathrm{mg}$ each $(P=.008)$, with the group of mice receiving 16 testis tissue fragments showing the highest and the group of mice receiving 2 fragments showing the lowest average graft weight $(P=.02$, Table 1$)$. The total weight of grafts per recipient mouse was higher in the groups of mice receiving 16 or 8 fragments, and lower in the groups of mice receiving 4 or 2 fragments $(P<.001$, Table 1$)$.

The absolute (in $\mathrm{mg}$ ) and relative weight, (index, in \%) of the vesicular glands at the time of sacrifice were higher in the group of mice receiving 16 testis tissue fragments than those in the group of mice receiving 2 fragments $(P=.007$, Table 1).

\subsection{Histological Evaluation of the Recovered Testis Grafts}

3.2.1. Tubular Diameter. The seminiferous cords diameter in newborn donor testis tissue was $47 \pm 1.1 \mu \mathrm{m}$ at the time of grafting. The tubular diameter in the grafts examined at 8 months postgrafting did not differ among the groups of recipient mice receiving various numbers of testis tissue fragments $(P=.4$, Table 1$)$.

3.2.2. Tubular Density. Neonatal donor testis tissue had a seminiferous tubular density of $95 \pm 6.1$ tubule cross sections $/ \mathrm{mm}^{2}$ at the time of grafting. Tubular density of the grafts recovered from recipient mice did not differ among the groups of recipient mice receiving different numbers of fragments $(P=.3$, Table 1$)$.

3.2.3. Tubular Morphology. At the time of grafting, the histology of neonatal donor testes showed interstitial tissue containing Leydig cells as well as seminiferous cords containing somatic Sertoli cells and gonocytes. At 8 months postgrafting, the retrieved xenografts had complete spermatogenesis, comparable to the expected status in agematched pig testes. Representative histological photomicrographs of the recovered testis tissue xenografts from different groups of recipient mice are shown in Figure 1. The most advanced germ cell type and the morphology of the seminiferous tubule cross sections were evaluated in the retrieved xenografts and the results were compared among groups as follows

Spermatozoa were observed within the lumen of seminiferous tubule cross sections in the testis tissue xenografts from the majority of the recipient mice in all four groups (the exceptions were grafts from one or two recipient mice in groups of mice receiving 2, 4, or 8 fragments at the time of grafting). The percentage of graft tubule cross sections containing spermatozoa, as the most advanced germ cell types present, did not differ among the four groups $(P=.6)$, and that of elongated spermatids only tended to differ among the groups $(P=.06$, Table 1$)$.

The percentage of seminiferous tubules with round spermatids, as the most advanced germ cell type, differed among groups $(P=.03)$, with higher values observed in grafts from the group of mice receiving 16 testis tissue fragments, compared with those receiving 2 fragments $(P<$ .02 , Table 1).

The difference in the percentage of graft tubular cross sections with spermatocytes, as the most advanced types of germ cell present, only approached significance $(P=.06)$, and those of the tubules with spermatogonia or only Sertoli cells did not differ among the four groups $(P=.97, .2$, resp., Table 1).

The percentage of degenerated seminiferous tubules in the xenografts varied among the groups $(P=.01)$, with those in the group of mice receiving 2 testis tissue fragments showing higher degenerated tubules than those in the groups of mice grafted with 4 or 8 fragments $(P=.02$, Table 1$)$.

Table 2 summarizes the results of correlation analysis between each of the measured outcomes of testis tissue xenografting and the average graft weight, total graft weight, or the mouse body weight. No significant correlations were found between the mouse body weight and the average or total graft weight. When significant correlations were present for the average graft weight and the different parameters of grafting outcome, they were positive in most cases and negative for the percentages of tubules with spermatogonia or Sertoli-cell-only. An almost similar pattern of correlations was observed for those of the total graft weight. The mouse body weight had positive significant correlations only with tubular diameter and a negative correlation with the percentage of tubules containing only Sertoli cells.

\section{Discussion}

Testis tissue xenografting has provided a novel in vivo culture system to study testis function and to preserve spermatogenic potential of immature donors from diverse mammalian 
TABLE 1: Characterization of testis tissue xenografts recovered from recipient mice at 8 months postgrafting.

\begin{tabular}{|c|c|c|c|c|}
\hline & \multicolumn{4}{|c|}{ Number of testis tissue fragments grafted (per mouse) } \\
\hline & 2 & 4 & 8 & 16 \\
\hline Number of mice analyzed* & 8 & 10 & 9 & 10 \\
\hline Mouse body weight (g) & $29 \pm 0.5$ & $29 \pm 1.5$ & $30 \pm 0.6$ & $32 \pm 0.9$ \\
\hline Graft recovery rate $(\%)$ & $86 \pm 9.2$ & $98 \pm 2.5$ & $90 \pm 8.7$ & $95 \pm 3.8$ \\
\hline Average graft weight (mg) & $106 \pm 38.0^{\mathrm{a}}$ & $196 \pm 25.5^{\mathrm{ab}}$ & $208 \pm 36.6^{\mathrm{ab}}$ & $278 \pm 39.4^{\mathrm{b}}$ \\
\hline Total graft weight (mg) & $192 \pm 76.2^{\mathrm{a}}$ & $704 \pm 82.2^{\mathrm{a}}$ & $1,619 \pm 289.9^{b}$ & $2,443 \pm 338.8^{\mathrm{b}}$ \\
\hline Vesicular gland index (\%) & $0.1 \pm 0.06^{\mathrm{a}}$ & $0.3 \pm 0.06^{\mathrm{ab}}$ & $0.3 \pm 0.05^{\mathrm{ab}}$ & $0.5 \pm 0.06^{\mathrm{b}}$ \\
\hline Vesicular gland weight (mg) & $35 \pm 16.7^{\mathrm{a}}$ & $84 \pm 16.1^{\mathrm{ab}}$ & $94 \pm 18.3^{\mathrm{ab}}$ & $154 \pm 21.9^{\mathrm{b}}$ \\
\hline Tubular diameter $(\mu \mathrm{m})$ & $126 \pm 18.2$ & $121 \pm 14.7$ & $141 \pm 9.1$ & $144 \pm 2.6$ \\
\hline Tubular density $\left(/ \mathrm{mm}^{2}\right)$ & $31 \pm 6.4$ & $39 \pm 3.4$ & $38 \pm 3.1$ & $32 \pm 1.6$ \\
\hline Spermatozoa (\% of tubules) & $17 \pm 7.5$ & $23 \pm 6.3$ & $26 \pm 6.1$ & $28 \pm 3.2$ \\
\hline Elongated spermatids (\% of tubules) & $4 \pm 1.9$ & $10 \pm 2.0$ & $8 \pm 2.1$ & $11 \pm 1.6$ \\
\hline Round spermatids (\% of tubules) & $3 \pm 1.3^{\mathrm{b}}$ & $8 \pm 2.2^{\mathrm{ab}}$ & $8 \pm 1.9^{\mathrm{ab}}$ & $11 \pm 1.5^{\mathrm{a}}$ \\
\hline Spermatocytes (\% of tubules) & $4 \pm 2.4$ & $16 \pm 3.4$ & $13 \pm 2.3$ & $12 \pm 2.7$ \\
\hline Spermatogonia (\% of tubules) & $4 \pm 1.9$ & $5 \pm 1.4$ & $4 \pm 1.6$ & $3 \pm 2.4$ \\
\hline Sertoli-cell only (\% of tubules) & $42 \pm 8.8$ & $28 \pm 6.4$ & $29 \pm 6.9$ & $21 \pm 3.0$ \\
\hline Degenerated (\% of tubules) & $27 \pm 5.7^{\mathrm{a}}$ & $11 \pm 3.3^{\mathrm{b}}$ & $12 \pm 1.6^{\mathrm{b}}$ & $14 \pm 2.6^{\mathrm{ab}}$ \\
\hline
\end{tabular}

Four groups of recipient mice were grafted with different numbers of porcine testis tissue fragments, and the xenografts were evaluated at 8 months postgrafting for spermatogenic development. Recipient mice were gonadectomized male nude mice and randomly assigned into groups receiving $2,4,8$, or 16 testis tissue fragments per mouse $\left(n=10\right.$ mice/group). ${ }^{*}$ The number of recipient mice per group that survived to the time of analysis at 8 months postgrafting (the original number was 10 mice per group). Graft recovery rate was defined as the relative number of visible xenografts retrieved compared with the number of fragments grafted. The average graft weight and histological evaluations were based on the recovered grafts. The average seminiferous tubule diameter and tubular density (the number of the seminiferous tubules $/ \mathrm{mm}^{2}$ ) were calculated in the largest cross section of the recovered grafts. For comparison, at the time of grafting, the donor tissue had seminiferous cords that were $47 \pm 1.1 \mu \mathrm{m}$ in diameter and at a density of $95 \pm 6.1 \mathrm{tubules} / \mathrm{mm}^{2}$. Data are presented as mean \pm SEM. ${ }^{\text {ab }}$ Values with different superscript letters within each row are significantly different $(P<.05)$.

species in a laboratory mouse [20,22]. This study represents the first systematic examination of the optimal number of testis tissue fragments for xenografting into recipient mice. Although it should be emphasized that in our study we have examined pig-to-nude mouse model for testis tissue xenografting which may not necessarily reflect the situation in testicular xenografting using other donor species.

As the source of donor tissue, we used piglet testes since the outcome of porcine testis tissue xenografting is well established $[5,14]$. We previously showed that the piglet testes from our source (a university-affiliated swine farm) are a homogenous supply of testis tissue [24]. For recipients, we used castrated male nude mice since they have been the conventional choice as recipients for testis tissue xenografting $[5,6,25]$. We also used testis tissue fragments that were of the same size $\left(\sim 1 \mathrm{~mm}^{3}\right.$ or $\left.\sim 5 \mathrm{mg}\right)$ as those in the majority of previous reports, but used 2, 4, or 16 donor fragments as compared with the conventional number of 8 fragments.

In the present study, the rate of graft recovery did not differ among the four groups of recipient mice (range, $86 \%-98 \%)$. However, not only was the total weight of the recovered grafts $\sim 12$-fold higher in the group of mice receiving 16 fragments than that of the group receiving 2 fragments, but interestingly the average graft weight was also $\sim 2.5$-fold as high in the 16-fragment group compared with that in the 2-fragment group of mice. This demonstrated that the recipient mouse is fully capable of supporting the development of a much larger mass of grafted donor testis tissue than routinely used.

In a recent report of testis tissue xenografting using donor lambs [26], two flat strips of testis tissue $(\sim 9 \times$ $5 \times 1 \mathrm{~mm}$ or $\sim 45 \mathrm{~mm}^{3}$ each) were grafted per recipient mouse and recovered after 4 months resulting in a growth of 2.4-fold in the size of grafts. Although in the latter study a direct comparison with the conventional size of testis fragments was not made, it may be deduced that the relative physical growth of the flat stripes of testis tissue per $\mathrm{mm}^{3}$ was much less than that of cube fragments used in our study. In other words, whereas in that study [26] an average $45 \mathrm{~mm}^{3}$-flat stripe grew by $\sim 2$-fold, an average $1 \mathrm{~mm}^{3}$-cube fragment in our study grew by $\sim 21,39,41$, or 55 -fold (in 2, 4, 8, or 16-fragement groups, resp.). Similarly, the expansion of the total mass of grafted tissue was also much higher using our small fragments than using flat stripes in the above study. For instance, given the available data from the two studies, even $8 \mathrm{~mm}^{3}\left(8 \times 1 \mathrm{~mm}^{3}\right)$ total mass of small cube fragments grafted per mouse in our study resulted in a greater expansion of the tissue (to $\sim 323 \mathrm{~mm}^{3}$ or $\sim 1,619 \mathrm{mg})$ than that of $90 \mathrm{~mm}^{3}\left(2 \times 45 \mathrm{~mm}^{3}\right)$ of flat stripes (to $\sim 216 \mathrm{~mm}^{3}$ or $\sim 1,080 \mathrm{mg}$ ). In the above study [26], it was also concluded that the percentage of grafts that survived and percentage of seminiferous tubules that developed spermatogenesis were the same as those reported after xenografting small fragments of ovine testis tissue [21]. The differential rate of growth between our observations and 


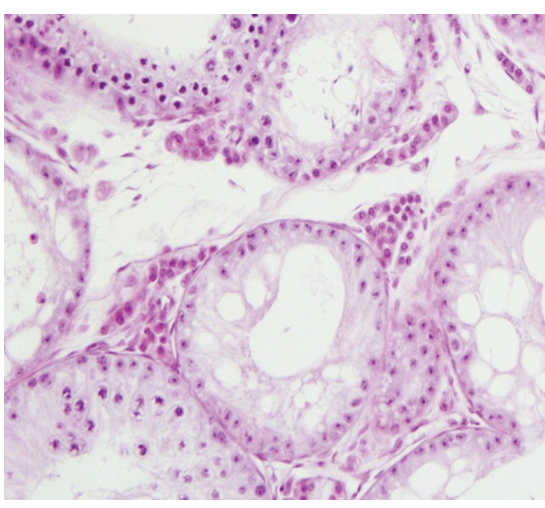

(a)

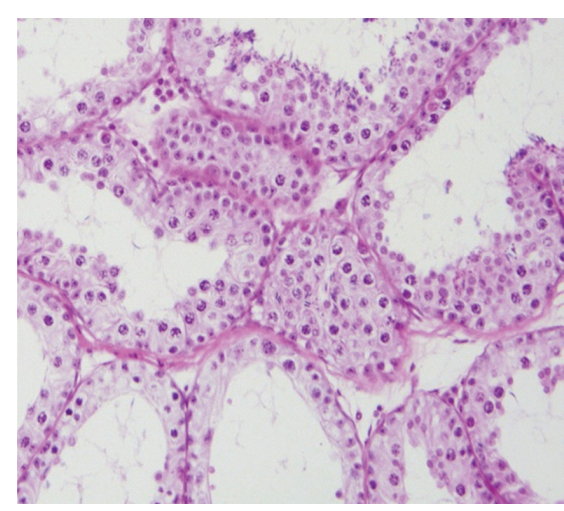

(b)

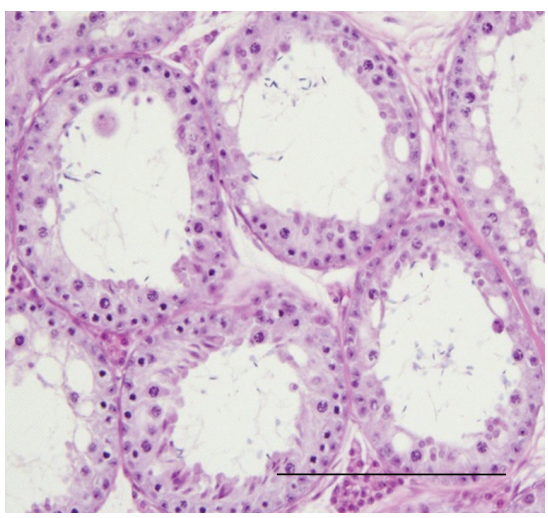

(d)

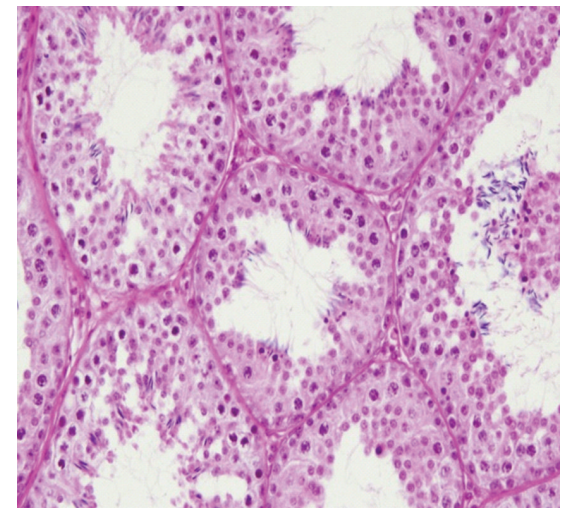

(c)

FIGURE 1: Histological photomicrographs of testis tissue xenografts recovered from recipient mice at 8 months post grafting. Representative xenografts from the group of recipient mice receiving 2 (a), 4 (b), 8 (c), or 16 (d) testis tissue fragments. The grafts from mice receiving 16 fragments were overall larger and more developed than those from mice receiving 2 fragments at the time of grafting. Scale bar $=200 \mu \mathrm{m}$.

TABLE 2: Correlations between the mouse body weight, average graft weight, or total graft weight and characteristics of testis tissue xenografts at the time of sacrifice at 8 months postgrafting.

\begin{tabular}{|c|c|c|c|c|c|c|}
\hline & \multicolumn{2}{|c|}{ Mouse body weight (g) } & \multicolumn{2}{|c|}{ Average graft weight (mg) } & \multicolumn{2}{|c|}{ Total graft weight (mg) } \\
\hline & $r$ & $P$ & $r$ & $\mathrm{P}$ & $r$ & P \\
\hline Mouse body weight (g) & - & - & 0.2 & .3 & 0.3 & .1 \\
\hline Graft recovery rate (\%) & -0.02 & .9 & 0.3 & .1 & 0.3 & .1 \\
\hline Average graft weight (mg) & 0.2 & .3 & - & - & 0.8 & .0001 \\
\hline Total graft weight (mg) & 0.3 & .1 & 0.8 & .0001 & - & - \\
\hline Tubular diameter $(\mu \mathrm{m})$ & 0.5 & .002 & 0.3 & .1 & 0.3 & .1 \\
\hline Tubular density $\left(\mathrm{mm}^{2}\right)$ & -0.1 & .4 & -0.01 & .9 & -0.04 & .8 \\
\hline Vesicular gland index (\%) & 0.1 & .4 & 0.4 & .02 & 0.4 & .02 \\
\hline Spermatozoa (\% tubules) & 0.07 & .1 & 0.5 & .01 & 0.5 & .001 \\
\hline Elongated spermatids (\% tubules) & 0.3 & .1 & 0.5 & .002 & 0.7 & .0001 \\
\hline Round Spermatids (\% tubules) & 0.3 & .07 & 0.5 & .001 & 0.6 & .0004 \\
\hline Spermatocytes (\% tubules) & 0.2 & .3 & -0.1 & .6 & 0.01 & .96 \\
\hline Spermatogonia (\% tubules) & -0.01 & .97 & -0.5 & .01 & -0.4 & .01 \\
\hline Sertoli-cell-only (\% tubules) & -0.4 & .02 & -0.5 & .01 & -0.6 & .0002 \\
\hline Degenerated (\% tubules) & 0.1 & .6 & -0.2 & .3 & -0.3 & .1 \\
\hline
\end{tabular}

Pearson's correlation coefficients $(r)$ were calculated for the combined data from four different groups of recipient mice grafted with different numbers of porcine testis tissue fragments, and the grafts evaluated at 8 months postgrafting for spermatogenic development. Correlation coefficients were considered significant when $P<.05$. 
those of the above study may be more due to the differences in shape of the grafted tissue, where small fragments may allow better vascularisation [27, 28]. Although differences in the species or sampling times cannot be ruled out in explaining these observation, in our experience with ovine testis tissue [21], these grafts reach physical growth and spermatogenic development earlier than those of the porcine tissue grafts and by 4 months postgrafting. Therefore, especially if the goal of testis tissue xenografting is to expand the limited tissue, such as when the donor is a rare or endangered immature individual, then using small fragments of testis tissue (of $\sim 1 \mathrm{~mm}^{3}$ ) is recommended.

The accessory sex glands, particularly the vesicular glands in mice, are highly androgen dependent and will regress to less than $10 \%$ of their normal weight (130-340 mg) within a few weeks after castration [16]. This process is reversible and therefore, measuring the weight of the vesicular glands in recipient mice castrated prior to testis tissue xenografting can be used as an assay to evaluate the production of bioactive androgens by the grafted testis tissue $[5,16]$. In the current study, the vesicular gland indices in the group of mice receiving 16 fragments were $\sim 5$-fold as high as those of mice receiving 2 fragments $(0.5 \%$ versus $0.1 \%$, resp.), likely as a consequence of higher mass of the testis tissue grafts capable of producing androgens. For comparison, the vesicular gland index in an intact 30 -gram nude mouse is $0.4 \%$ to $1.1 \%$ [16].

In the present study, spermatogenic development also differed among the groups since grafts from the group of mice receiving 16 fragments had $\sim 3$-fold more tubules with round spermatids (as the most advanced germ cell type) than those of the group of mice receiving 2 fragments. The grafts from the group of mice receiving 2 fragments also had about one third the percentages of tubule cross sections with elongated spermatids or spermatocytes but $\sim 2$-fold higher the percentage of degenerated tubules than those of other groups. These results collectively indicate that the grafts from the group of mice receiving 16 testis tissue fragments in general tended to yield grafts that were higher in tissue mass and were also more developed. This may be due to the higher levels of androgen produced from grafts in this group of recipient mice which might have had a positive effect on the gross and histological development of single grafts. This conclusion is also consistent with the results of our correlation analysis in which higher average or total graft weights were mostly correlated with indicators of graft development.

We also observed significant correlations between the average graft weight and most endpoint of testis tissue xenografting examined in the present study. Generally, bigger grafts tended to be more developed than smaller grafts.

\section{Conclusions}

The current study provided the first systematic evaluation of the effect of changing the number of tissue fragments on the outcome of testis tissue xenografting using a donor porcine model. This study demonstrated that total number of donor testis tissue fragments can be as many as 16 fragments for optimal results.

\section{Acknowledgments}

The authors thank Brian Andries and his staff, especially Margot Meiklejohn, at the Prairie Swine Center, M. Burmester, P. Mason, and their staff for animal care, Drs. G. Adams, A. Barth, and R. Mapletoft for critical review of the paper, University of Saskatchewan Western College of Veterinary Medicine for scholarships to S. Abbasi. This study was supported by grants from the Saskatchewan Health Research Foundation (SHRF) and the Natural Sciences and Engineering Research Council (NSERC) of Canada to A. Honaramooz. Portions of this study were presented at the 36th annual meeting of the International Embryo Transfer Society.

\section{References}

[1] L. D. Russell, R. A. Ettlin, A. P. SinhaHikim, and E. D. Clegg, Histological and Histopathological Evaluation of the Testis, Cache River, Shawnee College Road, Ill, USA, 1990.

[2] K. Gassei and S. Schlatt, "Testicular morphogenesis: comparison of in vivo and in vitro models to study male gonadal development," Annals of the New York Academy of Sciences, vol. 1120, pp. 152-167, 2007.

[3] M. Huleihel, M. Abuelhija, and E. Lunenfeld, "In vitro culture of testicular germ cells: regulatory factors and limitations," Growth Factors, vol. 25, no. 4, pp. 236-252, 2007.

[4] J. E. Parks, D. R. Lee, S. Huang, and M. T. Kaproth, "Prospects for spermatogenesis in vitro," Theriogenology, vol. 59, no. 1, pp. 73-86, 2003.

[5] A. Honaramooz, A. Snedaker, M. Boiani, H. Schöler, I. Dobrinski, and S. Schlatt, "Sperm from neonatal mammalia testes grafted in mice," Nature, vol. 418, no. 6899, pp. 778-781, 2002.

[6] S. Schlatt, S. S. Kim, and R. Gosden, "Spermatogenesis and steroidogenesis in mouse, hamster and monkey testicular tissue after cryopreservation and heterotopic grafting to castrated hosts," Reproduction, vol. 124, no. 3, pp. 339-346, 2002.

[7] A. Honaramooz, M.-W. Li, M. C. T. Penedo, S. Meyers, and I. Dobrinski, "Accelerated maturation of primate testis by xenografting into mice," Biology of Reproduction, vol. 70, no. 5, pp. 1500-1503, 2004.

[8] S. Schlatt, A. Honaramooz, J. Ehmcke et al., "Limited survival of adult human testicular tissue as ectopic xenograft," Human Reproduction, vol. 21, no. 2, pp. 384-389, 2006.

[9] A. K. Snedaker, A. Honaramooz, and I. Dobrinski, "A game of cat and mouse: xenografting of testis tissue from domestic kittens results in complete cat spermatogenesis in a mouse host," Journal of Andrology, vol. 25, no. 6, pp. 926-930, 2004.

[10] J. M. Oatley, D. M. de Avila, J. J. Reeves, and D. J. McLean, "Spermatogenesis and germ cell transgene expression in xenografted bovine testicular tissue," Biology of Reproduction, vol. 71, no. 2, pp. 494-501, 2004.

[11] R. Rathi, A. Honaramooz, W. Zeng, S. Schlatt, and I. Dobrinski, "Germ cell fate and seminiferous tuble development in bovine testis xenografts," Reproduction, vol. 130, no. 6, pp. 923-929, 2005.

[12] R. Rathi, A. Honaramooz, W. Zeng, R. Turner, and I. Dobrinski, "Germ cell development in equine testis tissue xenografted into mice," Reproduction, vol. 131, no. 6, pp. 1091-1098, 2006. 
[13] M. Abrishami, S. Abbasi, and A. Honaramooz, "The effect of donor age on progression of spermatogenesis in canine testicular tissue after xenografting into immunodeficient mice," Theriogenology, vol. 73, no. 4, pp. 512-522, 2010.

[14] A. Honaramooz, X.-S. Cui, N.-H. Kim, and I. Dobrinski, "Porcine embryos produced after intracytoplasmic sperm injection using xenogeneic pig sperm from neonatal testis tissue grafted in mice," Reproduction, Fertility and Development, vol. 20, no. 7, pp. 802-807, 2008.

[15] T. Shinohara, K. Inoue, N. Ogonuki et al., "Birth of offspring following transplantation of cyropreserved immature testicular pieces and in-vitro microinsemination," Human Reproduction, vol. 17, no. 12, pp. 3039-3045, 2002.

[16] S. Schlatt, A. Honaramooz, M. Boiani, H. R. Schöler, and I. Dobrinski, "Progeny from sperm obtained after ectopic grafting of neonatal mouse testes," Biology of Reproduction, vol. 68, no. 6, pp. 2331-2335, 2003.

[17] H. Ohta and T. Wakayama, "Generation of normal progeny by intracytoplasmic sperm injection following grafting of testicular tissue from cloned mice that died postnatally," Biology of Reproduction, vol. 73, no. 3, pp. 390-395, 2005.

[18] K. Jahnukainen, J. Ehmcke, and S. Schlatt, "Testicular xenografts: a novel approach to study cytotoxic damage in juvenile primate testis," Cancer Research, vol. 66, no. 7, pp. 3813-3818, 2006.

[19] M. Nakai, H. Kaneko, T. Somfai et al., "Production of viable piglets for the first time using sperm derived from ectopic testicular xenografts," Reproduction, vol. 139, no. 2, pp. 331$335,2010$.

[20] M. C. J. Paris and S. Schlatt, "Ovarian and testicular tissue xenografting: its potential for germline preservation of companion animals, non-domestic and endangered species," Reproduction, Fertility and Development, vol. 19, no. 6, pp. 771-782, 2007.

[21] L. Arregui, R. Rathi, S. O. Megee et al., "Xenografting of sheep testis tissue and isolated cells as a model for preservation of genetic material from endangered ungulates," Reproduction, vol. 136, no. 1, pp. 85-93, 2008.

[22] J. R. Rodriguez-Sosa and I. Dobrinski, "Recent developments in testis tissue xenografting," Reproduction, vol. 138, no. 2, pp. 187-194, 2009.

[23] M. Abrishami, M. Anzar, Y. Yang, and A. Honaramooz, "Cryopreservation of immature porcine testis tissue to maintain its developmental potential after xenografting into recipient mice," Theriogenology, vol. 73, no. 1, pp. 86-96, 2010.

[24] Y. Yang, M. Yarahmadi, and A. Honaramooz, "Development of novel strategies for isolation of piglet testis cells with high proportion of gonocytes," Reproduction, Fertility and Development, vol. 22, pp. 1-9, 2010.

[25] I. Dobrinski and R. Rathi, "Ectopic grafting of mammalian testis tissue into mouse hosts," Methods in Molecular Biology, vol. 450, pp. 139-148, 2008.

[26] J. R. Rodriguez-Sosa, R. A. Foster, and A. Hahnel, "Development of strips of ovine testes after xenografting under the skin of mice and co-transplantation of exogenous spermatogonia with grafts," Reproduction, vol. 139, no. 1, pp. 227-235, 2010.

[27] J. A. Schmidt, J. M. de Avila, and D. J. McLean, "Effect of vascular endothelial growth factor and testis tissue culture on spermatogenesis in bovine ectopic testis tissue xenografts," Biology of Reproduction, vol. 75, no. 2, pp. 167-175, 2006.

[28] S. Schlatt, B. Westernströer, K. Gassei, and J. Ehmcke, "Donorhost involvement in immature rat testis xenografting into nude mouse hosts," Biology of Reproduction, vol. 82, no. 5, pp. 888-895, 2010. 

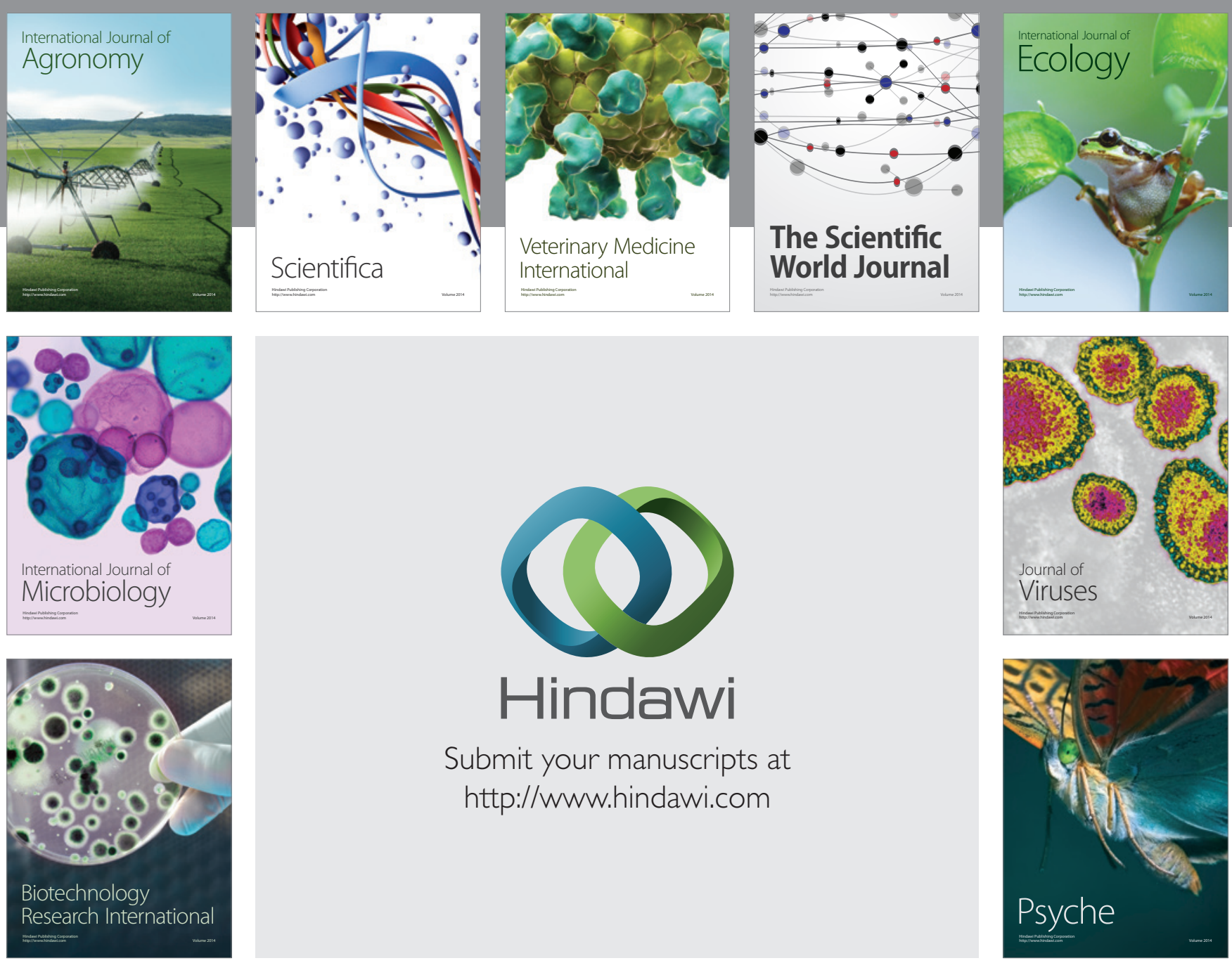

Submit your manuscripts at

http://www.hindawi.com
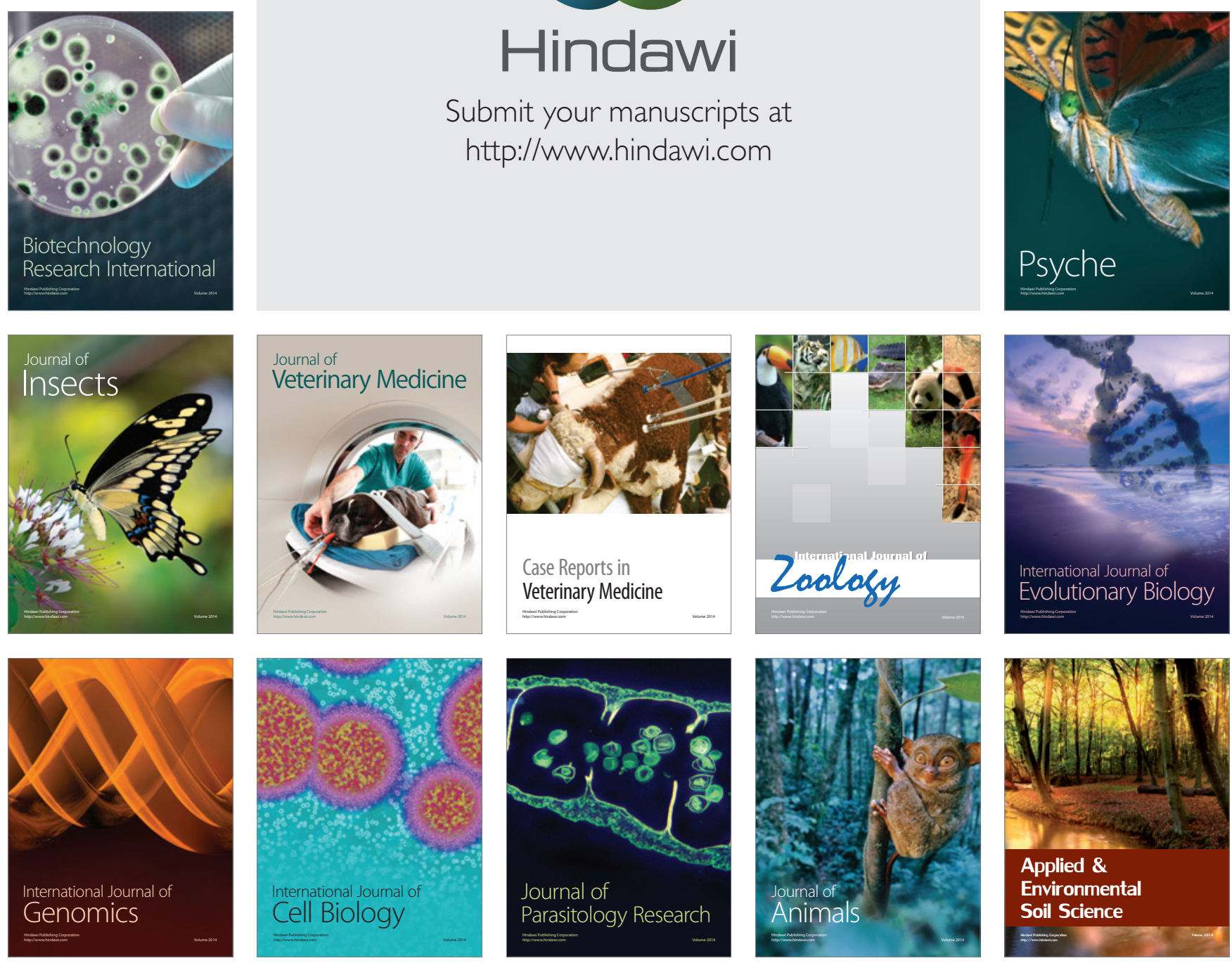